Key Words:

Exchange

Hydrogen

Retention:

10561,25 years

\title{
DEVELOPMENT OF A HYDROGEN ISOTOPE EXTRAPOLATION CURVE FOR PLATINUM CATYLIZED ZEOLITE
}

\author{
G. C. Staack
}

JULY 7, 2010

Savannah River National Laboratory Savannah River Nuclear Solutions

Aiken, SC 29808 


\section{DISCLAIMER}

This work was prepared under an agreement with and funded by the U.S. Government. Neither the U. S. Government or its employees, nor any of its contractors, subcontractors or their employees, makes any express or implied:

1. warranty or assumes any legal liability for the accuracy, completeness, or for the use or results of such use of any information, product, or process disclosed; or

2. representation that such use or results of such use would not infringe privately owned rights; or

3. endorsement or recommendation of any specifically identified commercial product, process, or service.

Any views and opinions of authors expressed in this work do not necessarily state or reflect those of the United States Government, or its contractors, or subcontractors.

Printed in the United States of America

Prepared for

U.S. Department of Energy 


\section{REVIEWS AND APPROVALS}

Gregory C. Staack, Author, Hydrogen Processing Group

Date

L. Kit Heung, Reviewer, Hydrogen Processing Group

Date

Thomas P. Varallo, Level 4 Manager, Hydrogen Processing Group

Date

- iii - 


\section{TABLE OF CONTENTS}

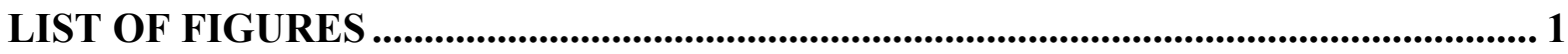

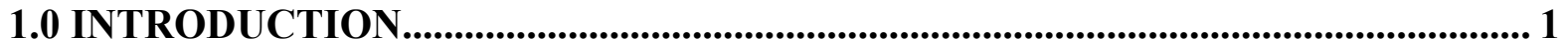

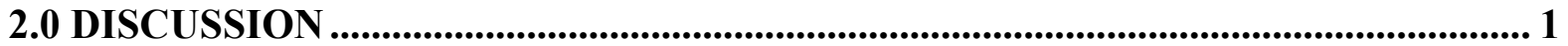

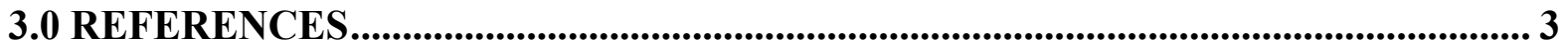

APPENDIX A. EXCHANGE DATA................................................................................ 4

APPENDIX B. EXAMPLE PROBLEM ................................................................................ 4 


\section{LIST OF FIGURES}

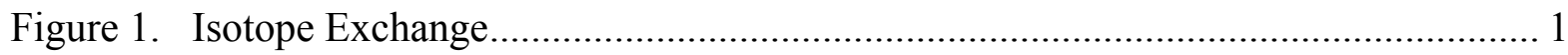

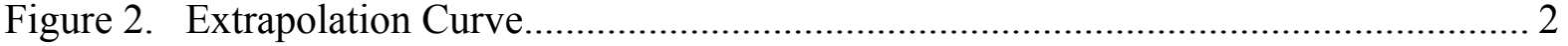


SRNL-STI-2010-00390 REVISION 0

\subsection{INTRODUCTION}

Experiments were conducted in 2003 and 2004 with protium and deuterium to demonstrate the hydrogen exchange properties of various catalyzed zeolites for tritium stripping purposes [1]. A column was loaded with the experimental material and purged with either $\mathrm{H}_{2}$ or $\mathrm{D}_{2}$ as shown in Figure 1 and the effluent monitored with a Prisma Quadrupole. The purge gas was switched when the column outlet concentrations reached $>95 \%$ of the purge isotope. Outlet concentrations were calculated as the sum of the purge isotope in the elemental form plus the purge isotope in the oxide form (the purge stream was humidified as it passed through the column) divided by the total hydrogen isotopes in the effluent. $1.5 \mathrm{wt} \%$ Pt on CBV 780 zeolite, manufactured by Zeolist International, had the best exchange characteristics, high capacity and fast kinetics, of the materials tested. This memorandum describes an approach to extrapolate previously unpublished hydrogen for deuterium exchange data collected earlier on $1.5 \mathrm{wt} . \%$ Pt on CBV 780 to lower concentrations for potential engineering applications.

Step 1. Deuterium Loading

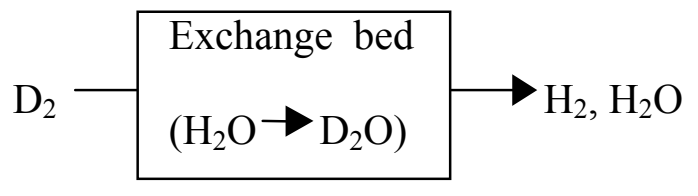

Step 2. Deuterium Exchange

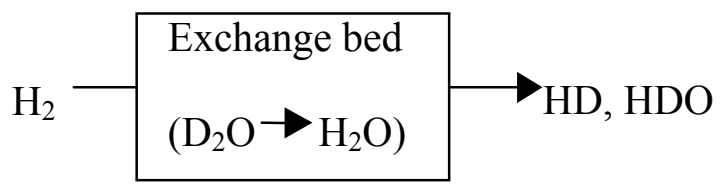

Figure 1. Isotope exchange.

\subsection{DISCUSSION}

It should be stressed that deuterium concentration in the effluent will likely differ from that in the zeolite itself. This is due to two factors with opposing effects. The effluent data provided in Appendix A represents the composition of the gas at the end of the column, and will therefore be higher than any other point in the column. The second factor is the existence of a separation factor between the oxide in the zeolite and the elemental isotope in the gas phase. Because oxide favors the heavier isotope, the deuterium concentration will be higher in the zeolite than in the gas phase. A more accurate experimental approach would involve desorbing the entire column and determining the isotopic composition of the oxide at various points during the exchange. This would allow closure of the mass balance loop and development of an extrapolation curve that would more accurately describe the relationship between the amount of purge gas passed through the column, residual heavy isotope concentration in the zeolite, and effluent concentration. Changes to the experimental parameters (ie. hydrogen isotopes, column dimensions, flow rate, mass of $\mathrm{Pt} / \mathrm{z}$ ), would necessitate the development of a new extrapolation curve. 
The test that generated the data contained in Appendix A was performed with $19.31 \mathrm{~g} \mathrm{of} \mathrm{Pt}$ catalyzed CBV 780 loaded in a $1 / 2$ " ID 6 " long bed. The zeolite was first purged with deuterium to convert oxides to $\mathrm{D}_{2} \mathrm{O}$. The material was then exchanged using $50 \mathrm{sccm}$ hydrogen at ambient temperature. A semi-log plot of the effluent deuterium concentration vs. time is given in Figure 2 and yields a curve that appears to be linear in two ranges. Data points below about $20 \%$ deuterium were selected for lower range extrapolation purposes as they gave the trendline with the highest $\mathrm{R}^{2}$ value. The equation can be generalized as:

$$
D_{f}=D_{o} e^{-0.02588 t}
$$

where $D_{o}$ and $D_{f}$ are the initial and final concentrations of deuterium in the effluent gas and $\mathrm{x}$ is the time in minutes required to reach the desired reduction. Because the experimental data is not linear throughout the entire measured range, regression of the lower range linear data gives a y-intercept, $D_{o}$, of about $57.5 \%$. This equation can be used to estimate the length of time (and therefore total amount of exchange gas) needed to reduce effluent concentrations below that of the measured data (less than 1\% deuterium). It is assumed for extrapolation purposes that the hydrogen gas used for the exchange gas is deuterium free.

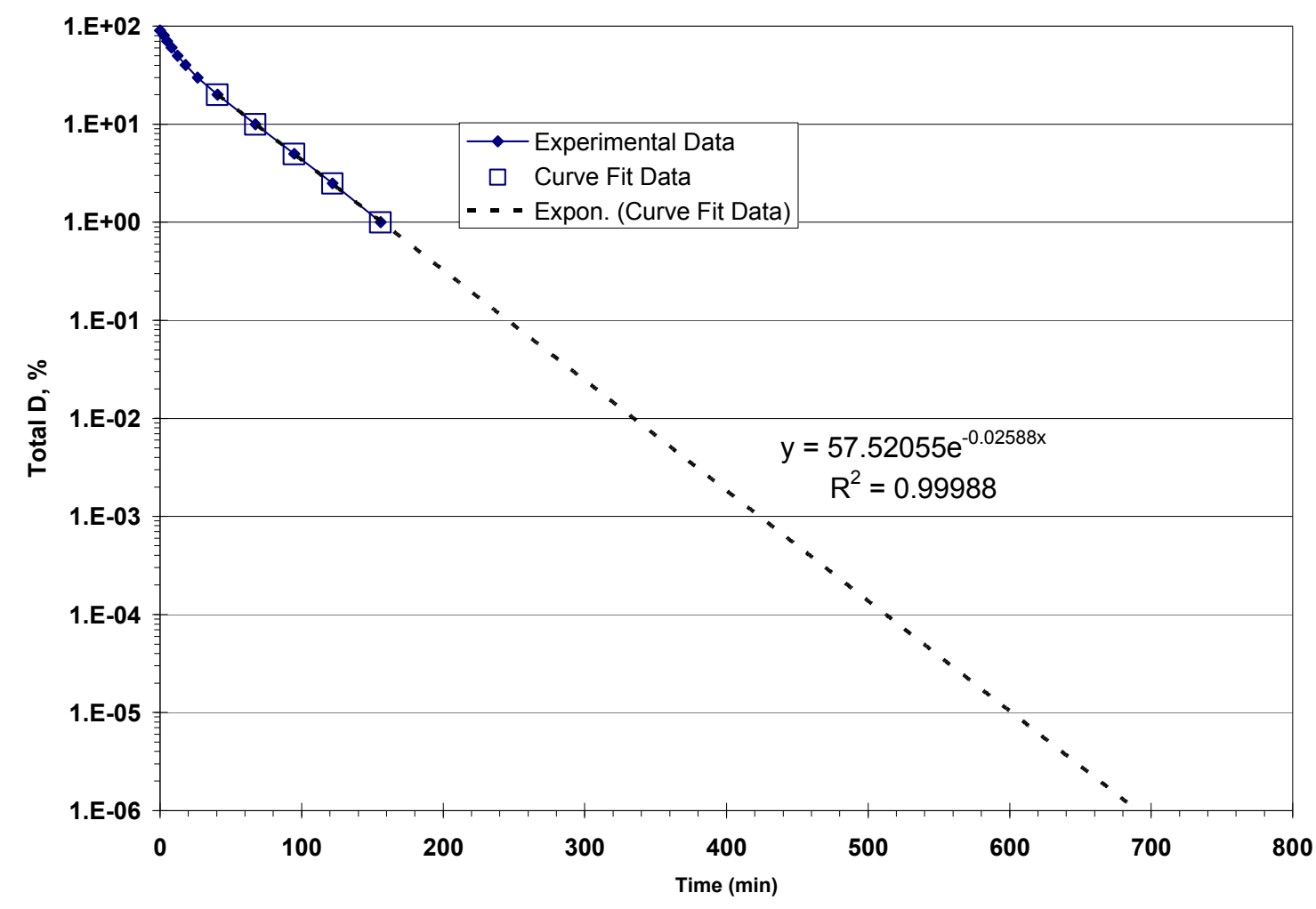

Figure 2. Extrapolation Curve.

Because the slope of the lower range data is less than the higher range data, extrapolation using the lower range data will give a conservative estimate of the time (and gas) needed to reduce the effluent concentration to desired output level. An example of the use of the extrapolation is given in Appendix B. 


\subsection{REFERENCES}

[1] Hydrogen Isotope Exchange Properties of Porous Solids Containing Hydrogen, L. K. Heung, G. C. Staack, Fusion Science and Technology, Volume 48, Number 1, July 2005, Pages 585-588. 


\section{APPENDIX A. Exchange Data}

\begin{tabular}{|c|c|}
\hline $\begin{array}{c}\text { Flow Duration } \\
(\min )\end{array}$ & $\begin{array}{c}\text { Total D } \\
\text { Concentration }\end{array}$ \\
\hline 0.00 & 90.16 \\
2.50 & 80.29 \\
5.01 & 70.56 \\
8.18 & 60.21 \\
12.35 & 49.90 \\
17.86 & 40.13 \\
26.54 & 29.97 \\
40.56 & 19.99 \\
67.43 & 10.01 \\
94.80 & 4.99 \\
121.84 & 2.50 \\
155.89 & 1.00 \\
\hline
\end{tabular}

\section{APPENDIX B. Example Problem}

Using the data in Appendix A and the equation shown in Figure 2, calculate the amount of gas required to reduce the deuterium concentration in the effluent gas from $10 \%$ to $0.003 \%$.

Solving $\mathrm{D}_{\mathrm{f}}=\mathrm{D}_{\mathrm{o}} \mathrm{e}^{-0.02588 \mathrm{t}}$ for time and inserting values for initial and final deuterium concentrations, gives:

$$
\frac{1}{0.02588} \ln \left(\frac{10}{0.003}\right)=313.4 \min
$$

For a flow rate of $50 \mathrm{sccm}$, this equates to $15.67 \mathrm{STP}-\mathrm{L}$ of hydrogen. 